\title{
Impact of Nonalcoholic Steatohepatitis on the Outcome of Patients Undergoing Roux-en-Y Gastric Bypass Surgery: a Propensity Score-Matched Analysis
}

\author{
Ziad Abbassi ${ }^{1}$. Lorenzo Orci ${ }^{1}$. Jeremy Meyer ${ }^{1}$. Sebastian Douglas Sgardello ${ }^{1}$. Nicolas Goossens ${ }^{2}$. \\ Laura Rubbia-Brandt ${ }^{3,4} \cdot$ Laurent Spahr $^{2}$ - Nicolas Christian Buchs ${ }^{1} \cdot$ Stefan Paul Mönig ${ }^{1}$. Christian Toso ${ }^{1}$. \\ Monika Elisabeth Hagen ${ }^{1} \cdot$ Minoa Karin Jung ${ }^{1}$ (i)
}

Received: 22 February 2021 / Revised: 28 July 2021 / Accepted: 30 July 2021 / Published online: 21 September 2021

(c) The Author(s) 2021

\begin{abstract}
Purpose It is currently unknown whether NASH (nonalcoholic steatohepatitis), as compared to simple steatosis, is associated with impaired postoperative weight loss and metabolic outcomes after RYGB surgery. To compare the effectiveness of Roux-en-Y gastric bypass (RYGB) on patients with NASH versus those with simple nonalcoholic fatty liver (NAFL). Materials and Methods We retrospectively retrieved data from 515 patients undergoing RYGB surgery with concomitant liver biopsy. Clinical follow-up and metabolic assessment were performed prior to surgery and 12 months after surgery. We used multivariate analysis of variance (MANOVA) and propensity score matching and we assessed for changes in markers of hepatocellular injury and metabolic outcomes.

Results There were 421 patients with simple NAFL, and 94 with NASH. Baseline alanine and aspartate aminotransferases were significantly higher in patients with NASH $(p<0.01)$. Twelve months after the RYGB surgery, as determined by both MANOVA and propensity score matching, patients with NASH exhibited a significantly greater reduction in alanine aminotransferase $(\beta$-coefficient $-12 \mathrm{iU} / 1[-22$ to -1.83$], 95 \% \mathrm{CI}$, adjusted $p=0.021)$ compared to their NAFL counterparts (31 matched patients in each group with no loss to follow-up at 12 months). Excess weight loss was similar in both groups ( $\beta$-coefficient $4.54 \%$ [ -3.12 to 12.21$]$, 95\% CI, adjusted $p=0.244)$. Change in BMI was comparable in both groups $(-14$ $(-16.6$ to -12.5$)$ versus $-14.3(-17.3$ to -11.9$), p=0.784)$.

Conclusion After RYGB surgery, patients with NASH experience a greater reduction in markers for hepatocellular injury and similar weight loss compared to patients with simple steatosis.
\end{abstract}

Keywords Non-alcoholic fatty liver disease $\cdot$ Non-alcoholic steatohepatitis · Outcome $\cdot$ Roux-en-Y gastric bypass $\cdot$ Propensity score matching $\cdot$ Bariatric surgery

Ziad Abbassi and Lorenzo Orci contributed equally to this work.

\section{Key Points}

1. Patients with NASH show a less marked weight loss after gastric bypass in unadjusted analysis

2. Propensity score matched patients with NASH and NAFL experience similar weight loss

3. Gastric bypass produces a significant reduction of alanine aminotransferase in patients with NASH

Minoa Karin Jung

minoa.jung@hcuge.ch

Extended author information available on the last page of the article

\section{Introduction/Purpose}

Nonalcoholic fatty liver disease (NAFLD) is the hepatic manifestation of the metabolic syndrome and encompasses a spectrum of clinicopathologic abnormalities that includes nonalcoholic fatty liver (NAFL or simple steatosis), nonalcoholic steatohepatitis (NASH), and liver cirrhosis and its complications [1,2]. Nonalcoholic fatty liver disease is a leading cause of the global burden of chronic liver disease, affecting up to a quarter of the general adult population, both in high- and low-income countries [3]. Eighty to $90 \%$ of obese people display NAFLD and it is estimated that $10-15 \%$ of these cases will eventually progress to liver fibrosis and cirrhosis [4]. On top of liver-specific morbidity 
and mortality, patients with NAFLD are at risk of coronary artery disease and type II diabetes, as well as various types of cancer [5, 6]. In the USA, models designed to predict the public health impact of NAFLD suggest that the number of cases may increase by $21 \%$, from 83.1 million in 2015 to 100.9 million in 2030 [7]. NAFL and NASH are both reversible conditions. In this regard, their alarming epidemiological rise emphasizes the need for the public health community to increase awareness and diagnosis of these conditions and to develop effective interventions.

In patients with morbid obesity, when exercise and diet interventions have failed, bariatric surgery may be indicated. While the benefits and risks of such interventions are well reported [8], there is only scarce evidence as to whether patients within distinct severity stages of NAFLD may experience different weight loss after Roux-en-Y gastric bypass (RYGB) surgery. Furthermore, it is currently unknown whether patients with more severe forms of NAFLD may expect the same benefit from RYGB as those with simple obesity-related fatty liver infiltration.

Such uncertainty is highlighted by the fact that some studies have reported that the severity of steatosis can increase after procedures such as jejunoileal bypass surgery [9]. Conflicting evidence suggests that rapid weight loss can either lead to a reduction in the degree of fatty liver infiltration, or may promote steatohepatitis [10]. While it is generally accepted that bariatric surgery is beneficial to patients with NAFLD, there is a lack of evidence comparing the outcome of RYGB in patients with simple steatosis and those with active NASH. Based on these observations, the primary aim of this study was to compare the effects of RYGB surgery in a large cohort of patients with either simple NAFL or established NASH.

\section{Materials and Methods}

\section{Patients Selection and Data Collection}

This study was approved by the Institutional Review Board (number 2019-00,318) and informed consent was waived. We retrospectively collected information on all patients undergoing RYGB with a concomitant liver biopsy at our center, between January 1997 and December 2013. Patients were divided in two groups: one comprising patients with simple liver steatosis and the other made up of patients with histologically proven NASH (i.e., with lobular inflammation).

We retrieved the following information: patients demographics, American Association of Anesthesiologists (ASA) score, body mass index (BMI), levels of aspartate and alanine aminotransferases (AST, ALT) in the blood, fasting glycemia $(\mathrm{mmol} / \mathrm{l})$, fasting insulinemia $(\mu \mathrm{U} / \mathrm{m})$, and obesity-related complications such as presence of type II diabetes (defined as fasting glycemia $>7 \mathrm{mmol} / \mathrm{l}$ or $\mathrm{HbA} 1 \mathrm{C}>6.5 \%$ or under antidiabetic medication) and elevated blood pressure (defined as blood pressure $>140 / 90 \mathrm{mmHg}$ or medication). Insulin resistance was determined through the homeostatic model assessment for insulin resistance (Homa-IR) [11]. The histological diagnosis of NASH was established based on the steatosis, activity, and fibrosis (SAF) score [12], as determined by a blind histological review of all slides by a senior hepatopathologist. Briefly, the SAF score attributes points according to the grade of liver steatosis, the degree of lobular inflammation, and the extension of fibrosis, while the severity of lobular inflammation determines whether steatohepatitis is present. Excess weight loss (EWL) was calculated as the percent postoperative reduction in body weight, based on an ideal BMI of $25 \mathrm{~kg} / \mathrm{m}^{2}$.

Clinical and biochemical outcomes were collected at baseline (before surgery) and at the 12-month follow-up visit.

\section{Surgical Technique}

The surgical technique was standardized and similar between the groups. A detailed description of the procedure is available elsewhere [13]. Briefly, a pneumoperitoneum was created using the Optiview (Endopath Xcel, Ethicon) technique, and a $20-30-\mathrm{cm}^{3}$ gastric pouch was constructed using blue or green cartridge staplers as clinically indicated. Next, a standard RYGB with a $150-\mathrm{cm}$ alimentary limb and a 75-cm biliopancreatic limb was tailored. In the laparoscopic approach, a mechanical circular gastrojejunal (GJ) anastomosis with a transorally inserted anvil or a linear GJ anastomosis was carried out, and a jejunojejunal (JJ) anastomosis was performed with a linear stapler. In the robotic approach, hand-sewn GJ and JJ anastomoses were carried out. A routine air and methylene blue leak test was performed at the end of the procedure.

\section{Statistical Analysis}

Because most of the assessed variables did not have a normal distribution, continuous outcomes were evaluated by calculating the median and interquartile range (IQR) and their comparison was performed with the Mann-Whitney $U$ test. The primary outcome of interest was the change in the ALT level in the blood, from baseline to 12 months after the RYGB surgery. Secondary outcomes of interest included EWL (\%) and changes in AST, fasting insulinemia, and Homa-IR. We first crudely compared the median change of these outcomes from baseline in NASH and NAFL patients, by using the Mann-Whitney $U$ test. Next, to further enhance the comparability of patients in the NAFL or the NASH group, we carried out a multivariable analysis 
of variance (MANOVA), adjusting for the following confounders: patient age, gender, baseline BMI, presence of type II diabetes, and ASA score. Finally, we included an additional approach, by using a logistic regression model to generate propensity scores, taking into account the same aforementioned confounders. The nearest matching neighbor algorithm was then used to achieve 1:1 propensity score matching. Statistical analyses were performed using SPSS (Version 22, SPSS Inc., Chicago, Illinois) and STATA (version 12, Stata Corp, College Station, Texas). All authors had access to the study data and reviewed and approved the final manuscript.

\section{Results}

During the period covered by our study, 551 patients underwent RYGB surgery with concomitant liver biopsy at our center. One year after surgery, $6.5 \%$ of patients were lost to follow-up; therefore, we analyzed data collected on 515 patients (Fig. 1). Based on the SAF score, there were 421 patients with liver steatosis (NAFL group) and 94 with active lobular inflammation (NASH group). Baseline clinical characteristics are shown in Table 1. Patients in the
NASH group were more commonly males, had higher glycemia, Homa-IR values, and levels of aminotransferases in the blood, and presented a more severe grade of liver steatosis. There was also a higher prevalence of type II diabetes and hypertension in the NASH group.

We first assessed outcomes in the whole cohort, comparing between-group changes from baseline to 12 months after the RYGB surgery. In the entire cohort, 3 patients in the NAFL group and 22 patients in the NASH group were lost to follow-up at 12 months. As shown in Table 2, we found that patients in the NASH group experienced a significantly greater reduction in ALT $(p<0.001)$, AST $(p<0.001)$, glycemia $(p<0.001)$, fasting insulinemia $(p=0.014)$, and Homa-IR $(p=0.001)$. At the end of follow-up, the NASH group still had a higher proportion of patients with type II diabetes compared to the NAFL group ( $9 \%$ vs. $1.5 \%, p=0.001)$. In this unadjusted analysis, patients in the NASH group displayed a less marked EWL compared to the patients in the NAFL group. The EWL was $71.9 \%(55.9-89.3 \%)$ in the NASH group vs. $77.3 \%(65.3-90.5 \%)$ in the NAFL group, $p=0.012$. Median change in BMI at 12 months was comparable in both groups $(-14.9(-17$ to -12.3$)$ vs $-14.6(-16.7$ to -11.45$), p=0.448)$.
Fig. 1 Flow chart. RYGB, Roux-en-Y gastric bypass; PSM, propensity score matching; ASA, American Society of Anaesthesiologist; BMI, body mass index

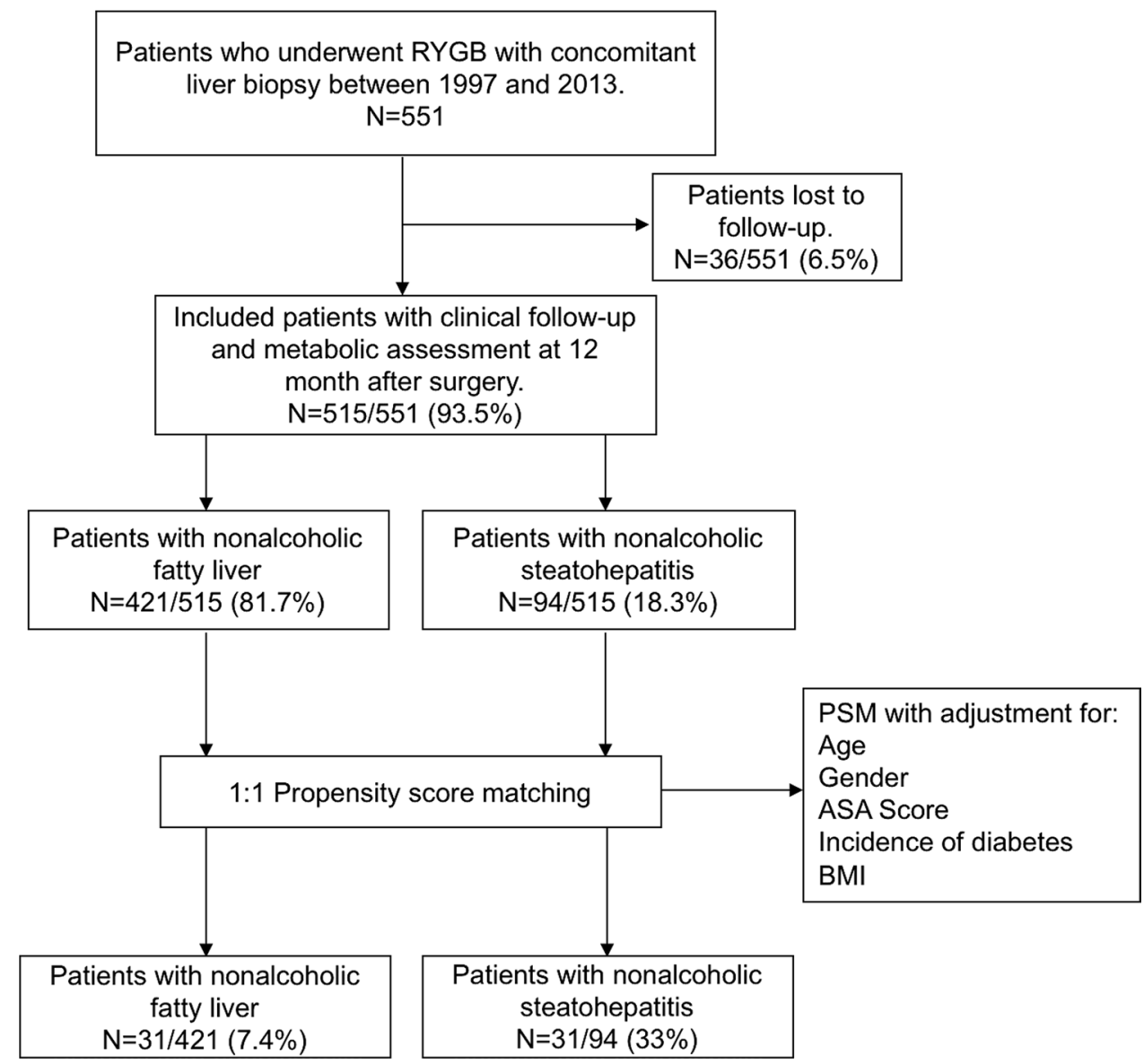


Table 1 Baseline characteristics and after propensity score matching

\begin{tabular}{|c|c|c|c|c|c|c|}
\hline & $\begin{array}{l}\text { Patients with } \\
\text { NAFL entire cohort } \\
(n=421)\end{array}$ & $\begin{array}{l}\text { Patients with NASH } \\
\text { entire cohort }(n=94)\end{array}$ & $p$ value & $\begin{array}{l}\text { Patients with NAFL } \\
\text { after PSM }(n=31)\end{array}$ & $\begin{array}{l}\text { Patients with } \\
\text { NASH after PSM } \\
(n=31)\end{array}$ & $p$ value \\
\hline Age (years), IQR & $40(33-49)$ & $45(39-52)$ & 0.0004 & $46(37-54)$ & $45(40-52)$ & 0.9494 \\
\hline Gender female, $n(\%)$ & $350(83 \%)$ & $52(55 \%)$ & $<0.0001 *$ & $18(58 \%)$ & $18(58 \%)$ & $1.0000 *$ \\
\hline ASA score, IQR & $2(2-3)$ & $3(2-3)$ & $<0.0001$ & $2(2-3)$ & $3(2-3)$ & 0.8011 \\
\hline BMI $\left(\mathrm{kg} / \mathrm{m}^{2}\right), \mathrm{IQR}$ & $43.3(41-47)$ & $44.5(41-49)$ & 0.0436 & $44.7(42-48)$ & $43.6(41.4-49)$ & 0.6573 \\
\hline AST (iU/l), IQR & $19(15-25)$ & $30(24-41)$ & $<0.0001$ & $18(15-24)$ & $30(25-41)$ & 0.0001 \\
\hline ALT (iU/l), IQR & $25(17-37)$ & $47(38-70)$ & $<0.0001$ & $25.5(16-38)$ & $53(41-70)$ & $<0.0001$ \\
\hline Liver steatosis (\%), IQR & $30(10-60)$ & $70(60-80)$ & $<0.0001$ & $40(15-60)$ & $72.5(60-90)$ & $<0.0001$ \\
\hline Glycemia (mmol/l), IQR & $5.8(5.2-6.6)$ & $6.8(5.8-9)$ & $<0.0001$ & $6.2(5.6-7)$ & $6.6(6.1-10.4)$ & 0.0732 \\
\hline Insulinemia (miU/l), IQR & $19.7(14-30)$ & $28(19.4-43.6)$ & $<0.0001$ & $20.5(17.2-28.5)$ & $32.5(19.2-62.5)$ & 0.0212 \\
\hline Homa-IR, IQR & $5.5(3.5-8.7)$ & $9.3(5.9-16.3)$ & 0.0031 & $3.6(2.6-5.5)$ & $4.4(2.8-8.4)$ & 0.3514 \\
\hline Type II diabetes, $n(\%)$ & $98(23 \%)$ & $45(48 \%)$ & $<0.0001 *$ & $13(42 \%)$ & $11(36 \%)$ & $0.2719 *$ \\
\hline Hypertension, $n(\%)$ & $139(33 \%)$ & $51(54 \%)$ & $<0.0001 *$ & $15(48 \%)$ & $13(42 \%)$ & $0.2605 *$ \\
\hline Triglycerides (mmol/l), IQR & $1.3(0.9-2)$ & $1.8(1.2-2.4)$ & $<0.0001$ & $1.4(1.2-2.1)$ & $1.8(1.22-2.11)$ & 0.2308 \\
\hline
\end{tabular}

Data show median and interquartile range (IQR), unless otherwise specified

Abbreviations: $N A F L$, nonalcoholic fatty liver; $N A S H$, nonalcoholic steatohepatitis; $A L T$, alanine aminotransferase; AST, aspartate aminotransferase; ASA, American Association of Anesthesiologists; BMI, body mass index; Homa-IR, homeostatic model assessment for insulin resistance. Data were compared using the Mann-Whitney $U$ test, unless specified otherwise. ${ }^{*}$ Chi-squared test

Table 2 Outcomes in the whole cohort

\begin{tabular}{|c|c|c|c|c|c|c|c|}
\hline & Patients with $\mathrm{N}$ & $\mathrm{L}(n=421)$ & & Patients with NAS & $\mathrm{H}(n=94)$ & & \\
\hline & $\begin{array}{l}\text { Baseline } \\
(n=421)\end{array}$ & $\begin{array}{l}12 \text { months } \\
(n=418)\end{array}$ & $\begin{array}{l}\text { Median change } \\
\text { from baseline }\end{array}$ & Baseline $(n=94)$ & $\begin{array}{l}12 \text { months } \\
(n=69)\end{array}$ & $\begin{array}{l}\text { Median change } \\
\text { from baseline }\end{array}$ & $p$ value* \\
\hline ALT(iU/l) & 25 (17 to 37$)$ & 21 (15 to 28$)$ & $-4(-14$ to 5$)$ & 47 (38 to 70$)$ & 26 (20 to 34$)$ & $\begin{array}{c}-22(-41 \\
\text { to }-10)\end{array}$ & $<0.001$ \\
\hline AST (iU/l) & 19 (15 to 25$)$ & 21 (17 to 26$)$ & $2.5(-4$ to 8$)$ & $30(24$ to 41$)$ & 23 (20 to 30$)$ & $\begin{array}{l}-5.5(-15.5 \\
\text { to } 4)\end{array}$ & $<0.001$ \\
\hline EWL (\%) & - & $\begin{array}{l}77.3 \text { (65.3 to } \\
90.5)\end{array}$ & - & - & $\begin{array}{l}71.9(55.9 \text { to } \\
83.3)\end{array}$ & - & 0.012 \\
\hline BMI $\left(\mathrm{kg} / \mathrm{m}^{2}\right)$ & 43.3 (41 to 47$)$ & $\begin{array}{l}29.2(26.6 \text { to } \\
32.2)\end{array}$ & $\begin{array}{l}-14.9(-17 \text { to } \\
-12.3)\end{array}$ & 44.5 (41 to 49$)$ & 29.9 (27.8 to 36$)$ & $\begin{array}{c}-14.6(-16.7 \\
\text { to }-11.45)\end{array}$ & 0.448 \\
\hline $\begin{array}{l}\text { Glycemia } \\
(\mathrm{mmol} / \mathrm{l})\end{array}$ & $5.8(5.2$ to 6.6$)$ & $4.78(4.4$ to 5.2$)$ & $\begin{array}{c}-1.02(-2 \\
\text { to }-0.5)\end{array}$ & 6.75 (5.8 to 9$)$ & 4.98 (4.6 to 5.6$)$ & $\begin{array}{c}-1.73(-2.87 \\
\text { to }-0.9)\end{array}$ & $<0.001$ \\
\hline $\begin{array}{l}\text { Insulinemia } \\
(\mu \mathrm{U} / \mathrm{L})\end{array}$ & 19.7 (14 to 30$)$ & $6.5(4.75$ to 8.45$)$ & $\begin{array}{c}-13.4(-22 \\
\text { to }-7.9)\end{array}$ & 28 (19.4 to 43.6$)$ & $9.1(7.5$ to 14$)$ & $\begin{array}{c}-22.5(-52.9 \\
\text { to }-10.3)\end{array}$ & 0.014 \\
\hline Homa-IR & $\begin{array}{l}5.46 \text { (3.48 to } \\
8.56)\end{array}$ & $\begin{array}{l}1.38(0.97 \text { to } \\
1.95)\end{array}$ & $\begin{array}{l}-3.87(-6.62 \\
\text { to }-2)\end{array}$ & $\begin{array}{c}9.27(5.93 \text { to } \\
16.32)\end{array}$ & $\begin{array}{l}2.01 \text { (1.52 to } \\
3.01)\end{array}$ & $\begin{array}{c}-8.92(-19.8 \\
\text { to }-3.18)\end{array}$ & 0.001 \\
\hline
\end{tabular}

Data show median and interquartile range, unless otherwise specified

Abbreviations: NAFL, nonalcoholic fatty liver; $N A S H$, nonalcoholic steatohepatitis; $A S T$, aspartate aminotransferase; $A L T$, alanine aminotransferase; $E W L$, excess weight loss; $B M I$, body mass index; Homa-IR, homeostatic model assessment for insulin resistance

${ }^{*} p$ value for the difference in median change from baseline

Next, we carried out a MANOVA test, adjusting for patient age, gender, baseline BMI, presence of type II diabetes, and ASA score (Table 3). Using this approach, we found that, compared to patients with simple steatosis, patients with NASH experienced a significantly greater adjusted decrease in ALT ( $\beta$ coefficient -12 iU/l $[-22$ to -1.83 ], $p=0.021)$, insulinemia $(\beta$ coefficient -10.76 $\mathrm{mIU} / 1$ [ -17.01 to -4.51$], p=0.001)$, and Homa-IR ( $\beta$ coefficient -5.01 [ -7.06 to -2.95$], p<0.001)$. In contrast, the adjusted impact of NASH on the reduction in AST ( $\beta$ coefficient $-1.81 \mathrm{iU} / 1$ [ -8.98 to 5.36], $p=0.619)$ and on 
EWL ( $\beta$ coefficient $4.54 \%$ [ -3.12 to 12.21$], p=0.244$ ) was no longer significant.

In another attempt to allow for confounding variables, we constructed propensity scores, adjusting for patient age, gender, baseline BMI, presence of type II diabetes, and ASA score. Using this approach, we identified $n=31$ pairs of NASH and NAFL patients that were otherwise comparable in terms of the aforementioned confounders. We reassessed changes from baseline to 12 months postRYGB surgery between these matched patients; no patient was lost to follow-up at 12 months (Table 4). Consistent with the MANOVA test, the results of the propensity score matching analysis indicated that patients in the NASH group displayed a significant reduction of ALT levels in the blood compared to patients with simple steatosis with a median change from baseline of $-25 \mathrm{iU} / \mathrm{l}(-38$ to -16$)$ in the NASH group vs. $-5 \mathrm{iU} / \mathrm{l}$ ( -21 to 4 ) in the NAFL group, $p=0.003$. Both groups experienced similar EWL and change in BMI. The results of the propensity score matching analysis further indicated a significant difference in terms of change in AST with a median change from baseline of $-7 \mathrm{iU} / \mathrm{l}(-15$ to -3$)$ in the NASH group vs. $3 \mathrm{iU} / \mathrm{l}(-3$ to 8$)$ in the NAFL group, $p=0.007$. There was a trend of borderline significance supporting a more marked reduction in fasting insulinemia in patients with NASH $(p=0.064)$, while Homa-IR changes were not significantly different between groups.

\section{Discussion}

The current study provides a head-to-head comparison of the impact of RYGB in patients with simple steatosis versus those with active steatohepatitis. The present study uses two different statistical approaches to adjust for baseline imbalance between groups, and results consistently indicate that patients with NASH experience similar excess weight loss as patients with simple steatosis, but a significantly greater reduction in alanine aminotransferase, 12 months post-surgery. The MANOVA test also uncovered some evidence that insulinemia and insulin resistance may decrease to a greater extent in patients with NASH. However, these findings could not be reproduced in the propensity score-matched analysis. Such discrepancy between the two statistical models may be explained either by (a) the presence of a type II error after propensity score matching (due to the limited sample size, $n=31$ matched pairs) or (b) overmatching. Taking type II diabetes into account in the matching process may have impacted the estimated differences in outcomes such as insulinemia and Homa-IR.

It is worth noting that the patients included in our study did not undergo a second liver biopsy at the end of followup. While this may be considered a limitation, one must acknowledge that a liver biopsy is a procedure that comes 
Table 4 Outcome assessment after propensity score matching

\begin{tabular}{|c|c|c|c|c|c|}
\hline \multicolumn{3}{|c|}{ NAFL patients $(n=31)$} & \multicolumn{3}{|c|}{ NASH patients $(n=31)$} \\
\hline $\begin{array}{l}\text { Baseline } \\
(n=31)\end{array}$ & $\begin{array}{l}12 \text { months } \\
(n=31)\end{array}$ & $\begin{array}{l}\text { Change from } \\
\text { Baseline }\end{array}$ & $\begin{array}{l}\text { Baseline } \\
(n=31)\end{array}$ & $\begin{array}{l}12 \text { months } \\
(n=31)\end{array}$ & $\begin{array}{l}\text { Change from } \\
\text { baseline }\end{array}$ \\
\hline
\end{tabular}
median change from baseline

\begin{tabular}{|c|c|c|c|c|c|c|c|}
\hline ALT (iU/l) & 25.5 (16 to 38$)$ & $19(15$ to 26$)$ & $-5(-21$ to 4$)$ & 53 (41 to 70 ) & 24 (20 to 32$)$ & $\begin{array}{c}-25(-38 \\
\text { to }-16)\end{array}$ & 0.003 \\
\hline AST (iU/l) & 18 (15 to 24$)$ & 23 (17 to 27 ) & $3(-3$ to 8$)$ & $30(25$ to 41$)$ & 23 (20 to 30 ) & $-7(-15$ to -3$)$ & 0.007 \\
\hline EWL (\%) & - & $\begin{array}{l}72.3(65.9 \text { to } \\
78.6)\end{array}$ & - & - & $\begin{array}{l}74.4 \text { (68.1 to } \\
80.7)\end{array}$ & & 0.598 \\
\hline $\begin{array}{l}\text { BMI change } \\
\left(\mathrm{kg} / \mathrm{m}^{2}\right)\end{array}$ & 44.7 (42 to 48$)$ & $\begin{array}{l}31.5(27.5 \text { to } \\
34.7)\end{array}$ & $\begin{array}{c}-14(-16.6 \\
\text { to }-12.5)\end{array}$ & 43.6 (41.4 to 49$)$ & $\begin{array}{l}29.8(27.6 \text { to } \\
33.1)\end{array}$ & $\begin{array}{c}-14.3(-17.3 \\
\text { to }-11.9)\end{array}$ & 0.784 \\
\hline Insulinemia & $\begin{array}{l}20.5 \text { (17.2 to } \\
28.5)\end{array}$ & 6.3 (4.9 to 8.6$)$ & $\begin{array}{c}-14.5(-18 \\
\text { to }-10.5)\end{array}$ & $\begin{array}{l}32.5(19.2 \text { to } \\
62.5)\end{array}$ & 9.1 (7.5 to 14$)$ & $\begin{array}{c}-24.8(-57.3 \\
\text { to }-8.5)\end{array}$ & 0.064 \\
\hline Homa-IR & $\begin{array}{l}3.60(2.58 \text { to } \\
5.50)\end{array}$ & $\begin{array}{l}1.39(1.04 \text { to } \\
2.18)\end{array}$ & $\begin{array}{c}-2.14(-3.37 \\
\text { to }-0.56)\end{array}$ & $\begin{array}{l}4.4(2.81 \text { to } \\
8.44)\end{array}$ & $\begin{array}{l}2.14(1.55 \text { to } \\
3.03)\end{array}$ & $\begin{array}{c}-1.76(-5.22 \\
\text { to }-1.022)\end{array}$ & 0.597 \\
\hline
\end{tabular}

Data show median \pm interquartile range

Abbreviations: $N A F L$, nonalcoholic fatty liver; $N A S H$, nonalcoholic steatohepatitis; $A L T$, alanine aminotransferase; $A S T$, aspartate aminotransferase; $E W L$, excess weight loss; Homa-IR, homeostatic model assessment for insulin resistance

with potential complications, and that this procedure is not ethically justifiable outside the scope of a dedicated prospective clinical trial. In this regard, there is a large body of evidence documenting that RYGB surgery has a beneficial impact on NAFLD/NASH-associated liver parenchymal abnormalities [14]. A recent meta-analysis indicated that 91\% of patients undergoing RYGB experienced a reduction in the histological severity of liver steatosis after surgery [15]. Consistent with these observations, a study by Winder et al. indicated a reduction in steatosis grade in $84 \%$ of patients after RYGB surgery [16]. When looking specifically at steatohepatitis, de Almeida et al. reported a complete resolution of necroinflammatory changes and an improvement of liver fibrosis in all NASH patients undergoing RYGB [17]. Similarly, Barker et al. showed that histological NASH features disappear in up to $89 \%$ of patients after RYGB surgery [18]. With these optimistic figures in mind, one must acknowledge that not all patients may be fully cured of NAFLD after RYGB [14]. In this regard, putative predictors of a poor improvement in liver histology after RYGB include refractory insulin resistance and limited postoperative weight loss $[19,20]$. However, the biological mechanisms explaining the failure of some patients to resolve liver parenchymal abnormalities remain elusive.

The main strength of our study is that the distinction of simple steatosis vs. active NASH was based on liver histology, which remains the gold-standard technique in this area [21, 22]. The histological assessment was done by a senior liver pathologist using the widely validated SAF score [12]. This approach confers robustness to our study by limiting potential misclassification, a source of error that commonly hampers the interpretation of retrospective studies. Moreover, our study, which is based on a large sample size $(n=515)$, is the first to provide a head-to-head comparison of NASH vs. simple steatosis in the context of RYGB surgery. Finally, the current results convey the clinically relevant message that patients with increasingly severe stages of NAFLD should not be prevented from undergoing RYGB, as they may benefit from this intervention to a similar extent as patients with milder forms of NAFLD.

However, our study also has limitations. First, it is based on a retrospectively collected data and therefore, it is by definition prone to some selection bias. For instance, we cannot rule out that dosage and duration of antidiabetic treatment may have differed between study groups, thereby impacting metabolic outcomes of the current study. Second, our follow-up period is relatively short. Hence, one may speculate that weight regain (which commonly occurs beyond 2 years after surgery) could lead to a recurrence of fatty liver infiltration, hepatocellular injury, and liver fibrosis [23, 24]. Third, as mentioned above, we did not repeat the liver biopsy at 12 months, because such a procedure is not recommended in routine care. Therefore, we could not evaluate whether the greater reduction in ALT in the NASH group was actually paralleled by a marked improvement in liver histology. Fourth, one may consider that our propensity score matching incorporates too many adjustment variables and that this may have led to both a marked lowering of the sample size and a likelihood of overmatching. With this limitation in mind, it is worth noting that main result of our study (that is, a greater reduction in ALT in NASH patients and a comparable EWL as compared to those with simple 
steatosis) was consistently identified both in the MANOVA test and the propensity score matching. Finally, while at the time of inclusion, none of the included patients was known for chronic alcohol intake (as assessed both clinically, and by liver histology), one cannot fully rule out a potential impact of alcohol on postoperative ALT values.

\section{Conclusion}

In summary, the current study compares for the first time the outcomes of patients with NASH versus those with simple steatosis after RYGB surgery. Our results indicate that patients with NASH are appropriate candidates for this surgical procedure, as evidenced by a more profound reduction in markers of hepatocellular injury with similar excess weight loss, as compared to obese counterparts with simple steatosis.

Supplementary Information The online version contains supplementary material available at https://doi.org/10.1007/s11695-021-05642-0.

Funding Open Access funding provided by Université de Genève.

\section{Declarations}

Ethical Approval All procedures performed in this study were in accordance with the ethical standards of the institutional and/or national research committee and with the 1964 Declaration of Helsinki and its later amendments or comparable ethical standards. Research Ethical Commission Identifying Number 2019-318, informed consent was waived. For this type of study, formal consent is not required.

Blinded Conflict of Interest Disclosure Statement Minoa Jung received personal fees from Intuitive Surgical Inc., Ethicon Inc., and Verb Surgical, outside this project. Monika Hagen received personal fees and nonfinancial support from Intuitive Surgical Inc., Quantgene Inc., Ethicon Inc., and Verb Surgical, outside this project. Christian Toso received personal fees from Intuitive Surgical Inc. and Johnson \& Johnson Inc., outside this project. For the remaining authors, none was declared.

Open Access This article is licensed under a Creative Commons Attribution 4.0 International License, which permits use, sharing, adaptation, distribution and reproduction in any medium or format, as long as you give appropriate credit to the original author(s) and the source, provide a link to the Creative Commons licence, and indicate if changes were made. The images or other third party material in this article are included in the article's Creative Commons licence, unless indicated otherwise in a credit line to the material. If material is not included in the article's Creative Commons licence and your intended use is not permitted by statutory regulation or exceeds the permitted use, you will need to obtain permission directly from the copyright holder. To view a copy of this licence, visit http://creativecommons.org/licenses/by/4.0/.

\section{References}

1. Glen J, Floros L, Day C, et al. Non-alcoholic fatty liver disease (NAFLD): summary of NICE guidance. BMJ. 2016;354:i4428.

2. Younossi Z, Koenig A, Abdelatif D, et al. Global epidemiology of nonalcoholic fatty liver disease - meta-analytic assessment of prevalence, incidence, and outcomes. Hepatology. 2016;64:73-84.

3. Younossi Z, Marchesini G, Pinto-Cortez H, et al. Epidemiology of nonalcoholic fatty liver disease and nonalcoholic steatohepatitis: implications for liver transplantation. Transplantation. 2019;103:22-7.

4. Pierantonelli I, Svegliati-Baroni G. Nonalcoholic fatty liver disease: basic pathogenetic mechanisms in the progression from NAFLD to NASH. Transplantation. 2019;103:e1-13.

5. Margini C, Dufour J. The story of HCC in NAFLD: from epidemiology, across pathogenesis, to prevention and treatment. Liver Int. 2016;36:317-24.

6. Younes R, Bugianesi E. Should we undertake surveillance for HCC in patients with NAFLD? J Hepatol. 2018;68:326-34.

7. Estes C, Razavi H, Loomba R, et al. Modeling the epidemic of nonalcoholic fatty liver disease demonstrates an exponential increase in burden of disease. Hepatology. 2018;67:123-33.

8. Chang S, Stoll C, Song J, et al. The effectiveness and risks of bariatric surgery: an updated systematic review and meta-analysis, 2003-2012. JAMA Surg. 2014;149:275-87.

9. Crespo J, Fernandez-Gil P, Hernandez-Guerra M, et al. Are there predictive factors of severe liver fibrosis in morbidly obese patients with non-alcoholic steatohepatitis? Obes Surg. 2001;11:254-7.

10. Luyckx F, Desaive C, Thiry A, et al. Liver abnormalities in severely obese subjects: effect of drastic weight loss after gastroplasty. Int J Obes Relat Metab Disord. 1998;22:222-6.

11. Antuna-Puente B, Disse E, Rabasa-Lhoret R, et al. How can we measure insulin sensitivity/resistance? Diabetes Metab. 2011;37:179-88.

12. Bedossa P. Utility and appropriateness of the fatty liver inhibition of progression (FLIP) algorithm and steatosis, activity, and fibrosis (SAF) score in the evaluation of biopsies of nonalcoholic fatty liver disease. Hepatology. 2014;60:565-75.

13. Buchs NC, Pugin F, Bucher P, et al. Learning curve for robot-assisted Roux-en-Y gastric bypass. Surg Endosc. 2012;26:1116-21.

14. Lassailly G, Caiazzo R, Pattou F, et al. Bariatric surgery for curing NASH in the morbidly obese? J Hepatol. 2013;58:1249-51.

15. Fakhry TK, Mhaskar R, Schwitalla T, et al. Bariatric surgery improves nonalcoholic fatty liver disease: a contemporary systematic review and meta-analysis. Surg Obes Relat Dis. 2019;15:502-11.

16. Winder J, Dudeck B, Schock S, et al. Radiographic improvement of hepatic steatosis after laparoscopic Roux-en-Y gastric bypass. Obes Surg. 2017;27:376-80.

17. de Almeida S, Rocha P, Sanches M, et al. Roux-en-Y gastric bypass improves the nonalcoholic steatohepatitis (NASH) of morbid obesity. Obes Surg. 2006;16:270-8.

18. Barker K, Palekar N, Bowers S, et al. Non-alcoholic steatohepatitis: effect of Roux-en-Y gastric bypass surgery. Am J Gastroenterol. 2006;101:368-73.

19. Lassailly G, Caiazzo R, Buob D, et al. Bariatric surgery reduces features of nonalcoholic steatohepatitis in morbidly obese patients. Gastroenterology. 2015;149:379-88.

20. Schwenger K, Fischer S, Jackson T, et al. In nonalcoholic fatty liver disease, Roux-en-Y gastric bypass improves liver histology while persistent disease is associated with lower improvements in waist circumference and glycemic control. Surg Obes Relat Dis. 2018;14:1233-9. 
21. Koch L, Yeh M. Nonalcoholic fatty liver disease (NAFLD): diagnosis, pitfalls, and staging. Ann Diagn Pathol. 2018;37:83-90.

22. Mahawar K, Parmar C, Graham Y, et al. Routine liver biopsy during bariatric surgery: an analysis of evidence base. Obes Surg. 2016;26:177-81.

23. Burza M, Romeo S, Kotronen A, et al. Long-term effect of bariatric surgery on liver enzymes in the Swedish Obese Subjects (SOS) study. PLoS One. 2013;8:e60495.

24. Jimenez L, Mendonca Chaim F, Mendonca Chaim F, et al. Impact of weight regain on the evolution of non-alcoholic fatty liver disease after Roux-en-Y gastric bypass: a 3-year follow-up. Obes Surg. 2018;28:3131-5.

Publisher's Note Springer Nature remains neutral with regard to jurisdictional claims in published maps and institutional affiliations.

\section{Authors and Affiliations}

Ziad Abbassi ${ }^{1}$ - Lorenzo Orci ${ }^{1}$. Jeremy Meyer ${ }^{1}$. Sebastian Douglas Sgardello ${ }^{1}$. Nicolas Goossens ${ }^{2}$. Laura Rubbia-Brandt ${ }^{3,4}$ • Laurent Spahr ${ }^{2}$. Nicolas Christian Buchs ${ }^{1}$ - Stefan Paul Mönig ${ }^{1}$. Christian Toso ${ }^{1}$. Monika Elisabeth Hagen ${ }^{1} \cdot$ Minoa Karin Jung ${ }^{1}$ (D)

1 Division of Visceral Surgery, Department of Surgery, Geneva University Hospitals and Faculty of Medicine, Rue Gabrielle-Perret-Gentil 4, 1211 Geneva 14, Switzerland

2 Division of Gastroenterology and Hepatology, Department of Medicine, Geneva University Hospitals and Faculty of Medicine, Geneva, Switzerland
3 Department of Pathology and Immunology, University of Geneva, Geneva, Switzerland

4 Division of Clinical Pathology, Geneva University Hospitals, Geneva, Switzerland 